\title{
Low Density Wood Impregnation with Water-Repellent Organosilicic Compounds
}

\author{
Guadalupe Canosa ${ }^{1,2}$, Paula V. Alfieri ${ }^{3}$, Carlos A. Giudice ${ }^{1 *}$ \\ ${ }^{1}$ UTN (Universidad Tecnológica Nacional), La Plata, Argentina \\ ${ }^{2}$ CIDEPINT (Centro de Investigación y Desarrollo en Tecnología de Pinturas), La Plata, Argentina \\ ${ }^{3}$ LEMIT (Laboratorio de Entrenamiento Multidisciplinario para la Investigación Tecnológica), La Plata, Argentina \\ Email: *cagiudice@yahoo.com
}

How to cite this paper: Canosa, G., Alfieri, P.V. and Giudice, C.A. (2018) Low Density Wood Impregnation with Water-Repellent Organosilicic Compounds. Journal of Materials Science and Chemical Engineering, 6, 39-51.

https://doi.org/10.4236/msce.2018.61006

Received: December 6, 2017

Accepted: January 5, 2018

Published: January 8, 2018

Copyright (๑) 2018 by authors and Scientific Research Publishing Inc. This work is licensed under the Creative Commons Attribution International License (CC BY 4.0).

http://creativecommons.org/licenses/by/4.0/

(c) (i) Open Access

\begin{abstract}
Many protective treatments for low density wood are applied by impregnation to give water-repellency and to control pathologies that usually have this substrate. The properties of Araucaria angustifolia, chemically modified by impregnation with methyltriethoxysilane, n-octyltriethoxysilane and mixtures of both in several ratios, were investigated to achieve mainly high dimensional stability, low capillary water absorption as well as satisfactory water vapor permeability. The aforementioned impregnants produce the wood chemical modification, involving the reaction of hydroxyl groups of the wood with the hydrolysis products of alcoxysilanes. It is concluded that the organosilicon polymers allow improving important characteristics of wood: 1) the non-occlusive coating keeps the water vapor permeability unaltered; 2 ) the alkoxysilane type defines the hydrophobicity and the continuity of coating formed on the pore wall and finally; 3) the polymeric structure formed after finishing sol-gel process incises both on the capillary water absorption and the dimensional stability. In addition, the studied treatments have the advantage of allowing that the water vapor, which permeates through the organosilicon coating placed on cell wall, can exit by hydrophobic repulsion and thus, prevent faults appearance generated by the condensed water inside of wood.
\end{abstract}

\section{Keywords}

Wood, Alkoxysilanes, Hydrophobicity, Water Vapor Permeability, Dimensional Stability

\section{Introduction}

Many protective treatments for low density wood are applied by impregnation to give water-repellency and to control pathologies that usually have this substrate 
(lack of dimensional stability, wet spots, microorganism growth, efflorescence, etc.) [1]-[6].

An efficient impregnant must substantially reduce water absorption of the substrate, present an adequate penetration and show an excellent resistance to environmental exposure [1] [2] [3] [4].

For impregnant selection, a central feature to consider is the pores size of substrate; these can be classified as: 1) micropores, with a radius smaller than $10^{-8}$ $\mathrm{m}$ : they do not present capillarity by steric hindrance to liquid water; materials with this pore size are hardly impregnable; 2) macropores, with a radius of between $10^{-8}$ y $10^{-4} \mathrm{~m}$ : they present capillarity; they are easily impregnable; and finally, 3) pores with a radius bigger than $10^{-4} \mathrm{~m}$ : in these materials, the capillarity does not occur. This behavior is easily visualized including the aforementioned pores radius in the expression $P=2 \gamma / r$, where $P$ is the excess of pressure that leads to the capillary rise, $\gamma$ the surface tension of the liquid and finally, $r$ the pore radius. In the three pores sizes, the water vapor passage is possible [7] [8] [9] [10].

The organic polymers often specified as impregnants (acrylic, polyurethanic, epoxy, etc.) usually block the pores decreasing the coefficient of capillary water absorption and the water vapor permeability; the latter limits the drying kinetics [11] [12].

The study of other impregnants led to the use of water-soluble alkali silicates as reactive treatments; nevertheless, silicification reaction to form inorganic polymers involves a slight acidification by solubilization of carbon dioxide from the air: the secondary formation of alkali carbonates makes that impregnation with silicates is disused today because of their tendency to form white spots [13] [14] [15] [16] [17].

Currently, consolidants and repellents based on organosilicon compounds are used in construction (e.g. brick, concrete, plaster, etc.), but they are not widely studied in wood.

The silanes most commonly used show hydrocarbon chains (linked by covalent bonds to the silicon) that may or may not be functionalized (e.g. with amino groups); to avoid yellowing generated by aromatic structures exposed to sunlight, the chains must be aliphatic. These hydrocarbon chains should have a length that facilities the kinetic of hydrolysis reaction during the sol-gel process (it improves with shorter chains) and gives hydrophobicity (it increases with chain length) [18] [19] [20] [21] [22].

By the above, the properties of Araucaria angustifolia, chemically modified by impregnation with alkylalkoxysilanes with different lengths of hydrocarbon chain, were studied in this paper in order to achieve mainly high dimensional stability, low capillary water absorption as well as satisfactory water vapor permeability.

\section{Materials and Methods}

The experiment included: 1) preparation of wood specimens; 2) choice of wood 
modifying reagents; 3) selection of sol-gel process conditions; 4) selection of impregnation conditions and finally; 5) laboratory tests.

\subsection{Preparation of Wood Specimens}

Araucaria angustifolia was selected because it is a macropores and moderately penetrable wood. Wood specimens, free of defects, were prepared with the proper size for each test. Since the hydroxyl groups of the cellulose have low reactivity [23], this was previously activated in a Soxhlet extractor with a solution of sodium hydroxide ( $\mathrm{pH} \mathrm{8.5)} \mathrm{for} 2$ hours; after finishing cellulose activation, the specimens were treated with distilled water for about 5 minutes to remove the alkali remaining on surface. In this process, it is generally observed a partial removal of hemicellulose and lignin.

\subsection{Choice of Wood Modifying Reagents}

Since the monomers derived from silicon with low molecular weight show a high reactivity with the hydroxyl groups of cellulose present in wood cell wall, the following alkylalkoxysilanes were selected: methyltriethoxysilane (MTES; chemical formula, $\mathrm{C}_{7} \mathrm{H}_{18} \mathrm{O}_{3} \mathrm{Si}$; $\mathrm{MW}, 178.3$; aspect, colorless liquid; density, 0.895 $\mathrm{g} \cdot \mathrm{cm}^{-3}$ ), n-octyltriethoxysilane (OTES; chemical formula, $\mathrm{C}_{14} \mathrm{H}_{32} \mathrm{O}_{3} \mathrm{Si}$; $\mathrm{MW}$, 276.5; aspect, colorless liquid; density, $0.880 \mathrm{~g} \cdot \mathrm{cm}^{-3}$ ) and mixtures of both in several volume ratios to obtain impregnants with different hydrophobicity.

\subsection{Selection of Sol-Gel Process Conditions}

The process involves the hydrolysis and condensation reactions of metal-organic precursors. Since the $\mathrm{pH}$ of the solution is an important variable because of the influence exerting on the final polymer form, it was considered convenient to select a neutral or slightly acid medium: the $\mathrm{pH}$ was adjusted by using acetic acid (conc.) until reaching $6.8 \pm 0.2$ value to form polymer films without high tridimensional particle growth.

The hydrolysis and condensation reactions lead to particle associations, which then are linked to form a single gel. After gelation, the system continues producing nanostructural and chemical changes (aging, which involves the expulsion of the liquid phase contained in the wood pores, i.e. water, alcohol and carrier solvent). At this stage, the polymerization reactions continue increasing the links $\equiv \mathrm{Si}-\mathrm{O}-\mathrm{Si} \equiv$ up to attain the hardening of the gel (xerogel film).

Simultaneously with the aforementioned reactions, the wood chemical modification also occurs. Many researchers have studied chemical modifications that involve the reaction of hydroxyl groups: bonds $\equiv \mathrm{Si}-\mathrm{O}-\mathrm{C} \equiv$ would arise from hydrolysis of alkoxides and the subsequent condensation of $\equiv \mathrm{Si}-\mathrm{OH}$ with the -OH of the wood [24]-[30].

\subsection{Selection of Impregnation Conditions}

This process was carried out at $45^{\circ} \mathrm{C}-50^{\circ} \mathrm{C}$ in an autoclave equipped with va- 
cuum pump and compressor, under controlled operating conditions. The autoclave was initially charged with the wood specimens; then, it was applied a vacuum of $500 \mathrm{~mm} \mathrm{Hg}$ for 10 minutes to release air and water vapor from the cells and facilitate the penetration of chemical modifier.

Later, the corresponding alkoxide solution was added without decreasing the vacuum level. In all cases, the 3/1 impregnant solution/wood ratio v/v was selected to ensure the complete submerging of wood specimens during the entire process.

The operating conditions were adjusted to achieve similar weight gains of chemical modifiers: the pressure was gradually increased from 1.5 to $6.5 \mathrm{~kg} \cdot \mathrm{cm}^{-2}$ for facilitating the penetration; this stage lasted from 15 to 60 minutes. Then, a slight vacuum was applied (about $200 \mathrm{~mm} \mathrm{Hg}$ for 10 minutes) to make possible the elimination of alkoxide excess on the wood specimen surface.

Later, the wood specimens were removed after reaching atmospheric pressure; finally, they were exposed into a chamber under controlled temperature and humidity conditions $\left(20^{\circ} \mathrm{C} \pm 2{ }^{\circ} \mathrm{C}\right.$ and $\left.60 \% \pm 5 \% \mathrm{RH}\right)$ for three weeks for allowing the gelation and aging.

For all specimens, average weight gain was $3.1 \% \pm 0.1 \% \mathrm{w} / \mathrm{w}$; it was determined by using Equation (1):

$$
W G=[(W m-W o) / W o]
$$

where Wo is the weight of pretreated wood specimens and $W m$ the weight of chemically modified ones (the quoted $W o$ and $W m$ correspond to oven-dried specimens at $100^{\circ} \mathrm{C} \pm 3^{\circ} \mathrm{C}$ up to constant weight), Figure 1.

\subsection{Laboratory Tests}

The terms dimensional stability and capillary water absorption are often used interchangeably as if they were synonyms: the effectiveness a treatment to reach dimensional stability can be defined as its ability to reduce or prevent the swelling/shrinking of wood resulting from absorption/desorption of moisture. In contrast, the effectiveness of water-repellent treatment can be defined as the
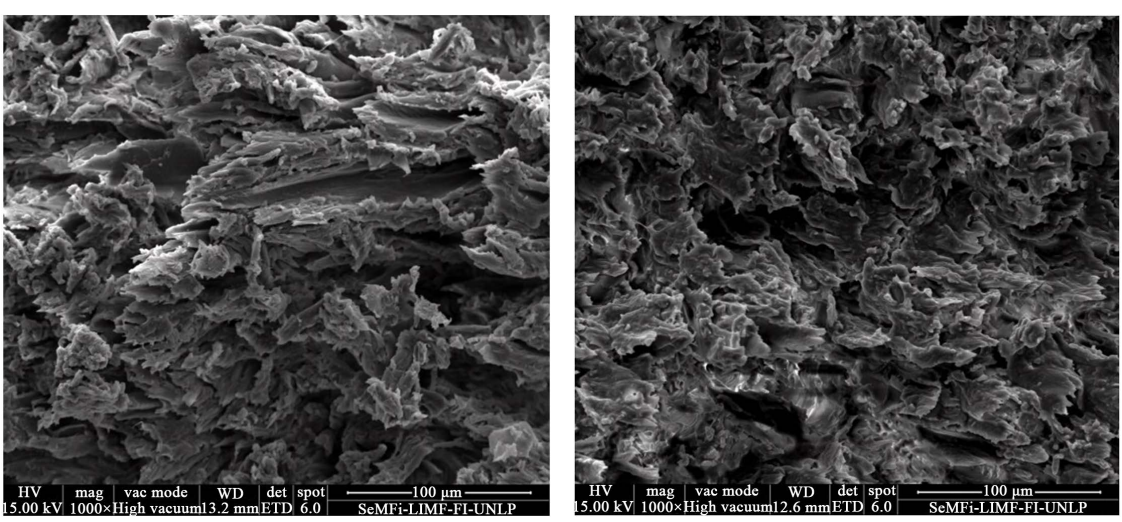

Figure 1. SEM of specimens of Araucaria angustifolia before (left) and after impregnation (right). 
ability to prevent or control the rate of liquid water uptake. As a consequence, they were considered in separate way.

Additionally, the water vapor permeability was determined; this property is important since the wood must be permeable to water vapor such that moisture accumulated inside it can go outside in vapor form for drying the material in order to reduce the causes of deterioration.

All the assays were performed by triplicate:

Dimensional stability: The specimen sizes were $20 \times 20 \times 20 \mathrm{~mm}$. The degree of dimensional stability was determined by calculating the Volumetric Swelling Coefficient $S$ and the Anti-Swell Efficiency ASE.

Water saturation was assessed by using the ASTM D 4442. The specimens were immersed in distilled water at $20^{\circ} \mathrm{C} \pm 2^{\circ} \mathrm{C}$ for 24 hours; then, they were removed, excess water was drained and the volume determined by the mercury displacement method. Finally, the specimens were oven-dried at $100^{\circ} \mathrm{C} \pm 3^{\circ} \mathrm{C}$ and the volumes were measured again by the aforementioned method.

Finally, the $S$ was calculated by using Equation (2):

$$
S, \%=100 \times\left(V_{2}-V_{1}\right) / V_{1}
$$

where $V_{2}$ and $V_{1}$ are respectively the volumes of saturated and oven-dried specimens.

Because the amount of swelling that occurs in wood depends on the density $\delta$ and on the fiber saturation point $K f$, the latter was calculated from Equation (3):

$$
S, \%=K f \times \delta
$$

Regarding efficiency $A S E$, it was calculated by using Equation (4):

$$
A S E, \%=100 \times(S s-S m) / S s
$$

where $S s$ and $S m$ are the average coefficients $S$ of unmodified and modified samples, respectively.

Finally, in a second cycle, $S$ and $A S E$ values were calculated to evaluate the leachability of residual nomers to obtain an estimated curing degree during the sol-gel process. For this purpose, the specimens were immersed in isopropyl alcohol for 2 hours, oven-dried at $100^{\circ} \mathrm{C} \pm 3^{\circ} \mathrm{C}$; then, the immersion process was repeated in distilled water at $20^{\circ} \mathrm{C} \pm 2^{\circ} \mathrm{C}$ for 24 hours.

Capillary water absorption: The specimen sizes were $80 \times 80 \times 40 \mathrm{~mm}$ (radial $\mathrm{x}$ tangential $\mathrm{x}$ axial). The test was carried out according to the guidelines of ISO 15148.

The specimen side faces were waterproofed with bituminous enamel. The specimens were placed into a convection oven at controlled temperature and humidity $\left(50^{\circ} \mathrm{C}\right.$ and $23 \%$, respectively), up to constant weight $\left(W_{1}\right)$.

Subsequently the samples were placed on a rack with only the test face $(80 \times$ $80 \mathrm{~mm}$ ) submerged in distilled water, at a constant depth of $2 \mathrm{~mm}$. After immersion for $24 \mathrm{~h}$, the specimens were removed, superficially dried with paper and weighed $\left(W_{2}\right)$.

Water vapor permeability: The specimen sizes were $80 \times 80 \times 5 \mathrm{~mm}$ (radial $\times$ 
tangential $\times$ axial). The test was carried out according to the guidelines of ISO 7783-2.

First, the corresponding test specimens were placed in an atmosphere with a saturated solution of ammonium dihydrophosphate (constant relative humidity of $93 \%$ ) up to constant weight. Then, the samples were placed in standard conditions $\left(23^{\circ} \mathrm{C}\right.$ and $\left.50 \% \mathrm{RH}\right)$ for 120 hours and they were weighed again. The water vapor permeability was calculated by dividing the weight decrease for each specimen by the testing time and its area.

\section{Results and Discussion}

\subsection{Dimensional Stability}

As known, the wood cell wall is mainly composed of polymers with hydroxyl and other oxygen-containing groups, which attract moisture through hydrogen bonding. As water is added to the cell wall, wood volume increases nearly proportionally to the volume of water added. Swelling increases until the cell wall is saturated: this point is called fiber saturation point. This process is reversible, and wood shrinks as it loses moisture below the fiber saturation point. Furthermore, wood also stocks water outside of the fibers, which does not contribute to swelling (no influence on the dimensional stability); this is called free water and it is found in the empty cell structures and/or interstitial spaces.

By the above, the dimensional changes were studied through S and ASE coefficients, Table 1.

Regarding $\mathrm{S}$, the values for unmodified specimens were similar for both cycles of immersion; this would be based on that extractives were removed in the cellulose activation stage and on the high degree of cured of alkoxides (low level of n-omers remainder).

Table 1. Laboratory results of S, ASE and w.

\begin{tabular}{|c|c|c|c|c|c|c|}
\hline \multirow{2}{*}{\multicolumn{2}{|c|}{ Alkoxide }} & \multicolumn{2}{|c|}{ S, \% } & \multicolumn{2}{|c|}{ ASE, \% } & \multirow{2}{*}{$\mathrm{w}, \mathrm{kg} \cdot \mathrm{m}^{-2} \cdot \mathrm{h}^{-1 / 2}$} \\
\hline & & Cycle I & Cycle II & Cycle I & Cycle II & \\
\hline \multicolumn{2}{|c|}{ Methyltriethoxysilane } & $7.67 \pm 0.28$ & $7.87 \pm 0.34$ & 31.76 & 30.29 & $2.26 \pm 0.11$ \\
\hline \multicolumn{2}{|c|}{ n-octhyltriethoxysilane } & $3.72 \pm 0.22$ & $3.81 \pm 0.20$ & 66.90 & 66.25 & $0.23 \pm 0.01$ \\
\hline \multirow{9}{*}{$\begin{array}{c}\text { MTES/OTES, } \\
\text { ratio v/v }\end{array}$} & $10 / 90$ & $3.33 \pm 0.19$ & $3.41 \pm 0.21$ & 70.37 & 69.80 & $0.25 \pm 0.01$ \\
\hline & $20 / 80$ & $3.12 \pm 0.17$ & $3.08 \pm 0.15$ & 72.24 & 72.72 & $0.30 \pm 0.03$ \\
\hline & $30 / 70$ & $2.85 \pm 0.14$ & $2.97 \pm 0.11$ & 74.64 & 73.69 & $0.37 \pm 0.02$ \\
\hline & $40 / 60$ & $2.60 \pm 0.15$ & $2.61 \pm 0.13$ & 76.87 & 76.88 & $0.43 \pm 0.03$ \\
\hline & $50 / 50$ & $2.48 \pm 0.13$ & $2.54 \pm 0.16$ & 77.94 & 77.50 & $0.61 \pm 0.03$ \\
\hline & $60 / 40$ & $2.81 \pm 0.14$ & $2.72 \pm 0.17$ & 75.00 & 75.91 & $0.85 \pm 0.04$ \\
\hline & $70 / 30$ & $3.25 \pm 0.18$ & $3.13 \pm 0.13$ & 71.08 & 72.28 & $1.25 \pm 0.07$ \\
\hline & $80 / 20$ & $4.32 \pm 0.25$ & $4.54 \pm 0.27$ & 61.56 & 59.79 & $1.52 \pm 0.08$ \\
\hline & $90 / 10$ & $5.85 \pm 0.26$ & $5.72 \pm 0.26$ & 47.95 & 49.34 & $1.90 \pm 0.08$ \\
\hline \multicolumn{2}{|c|}{ Reference } & $11.24 \pm 0.36$ & $11.29 \pm 0.35$ & - & - & $2.41 \pm 0.12$ \\
\hline
\end{tabular}


In the cases of wood only modified with MTES, the results indicate that a dense and compact coating would be formed on the pore wall improving the performance with respect to untreated wood due to its chemical modification. Nevertheless, it is not sufficient to prevent the inlet of water in liquid state because polymerized MTES does not present high water-repellency.

On the other hand, wood treated with only OTES also would form a hydrophobic coating and discontinuous by steric hindrance; this would support the better dimensional stability compared to untreated wood and even with those treated with MTES.

With respect to mixtures of alkoxides, the results indicate that the increased level of OTES initially led to a decrease of $S$ and then to an increase thereof, Figure 2. $S$ values in 50/50 ratio are the lowest $(S=2.48 \pm 0.13$, cycle I and 2.54 \pm 0.16 , cycle II), which bases the reduced and acceptable swelling; the values near to that ratio are equally acceptable.

The initial decrease of $S$ with the addition of OTES would be attributable to that the compact coating formed on the pore wall increases its hydrophobicity; this is based on that OTES is more hydrophobic than MTES by having a longer hydrocarbon chain, Figure 3.

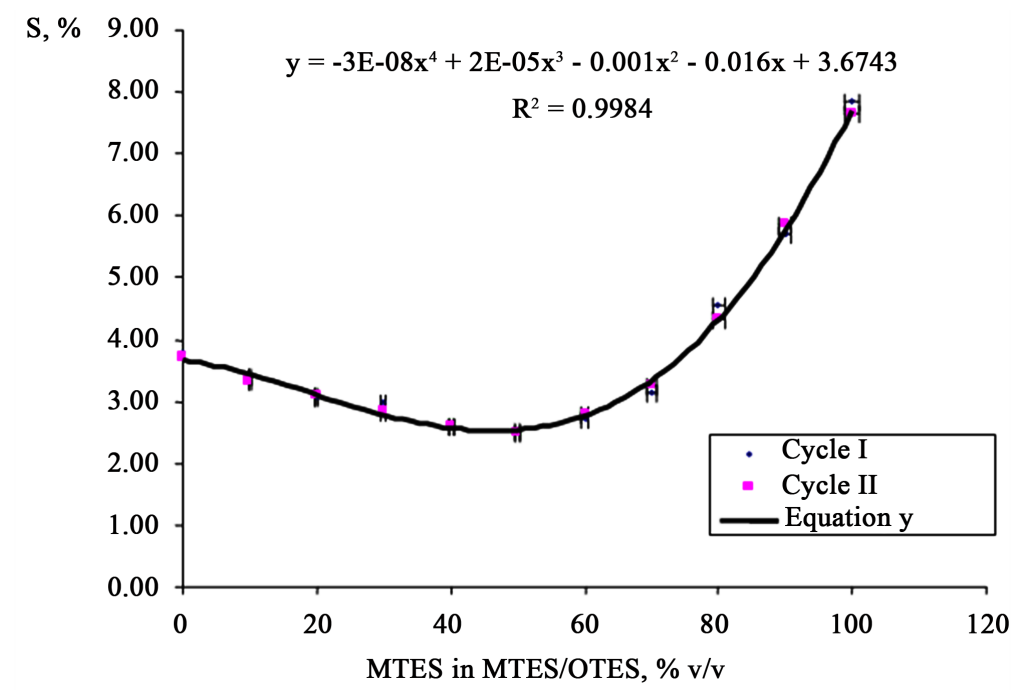

Figure 2. S variation vs. MTES concentration in the impregnant.
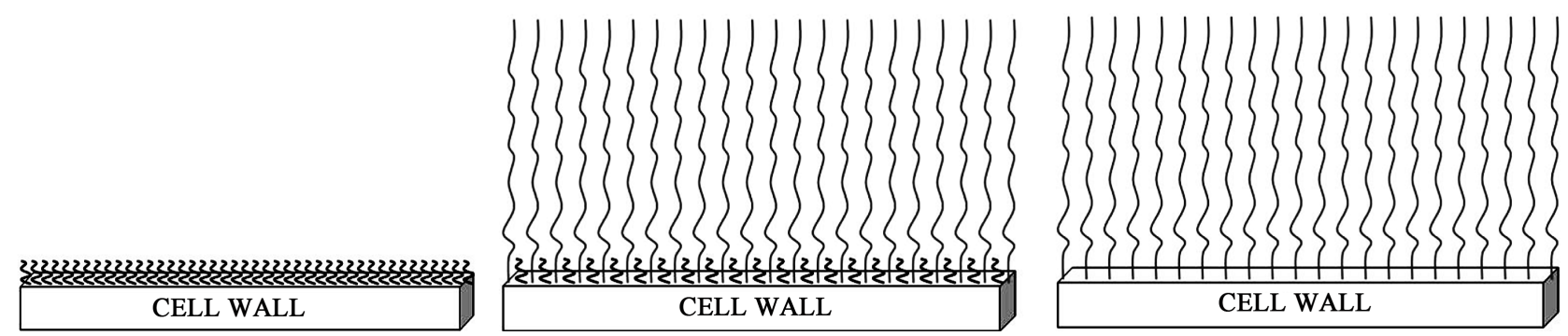

Figure 3. Hypothetical coating structure on pore wall: left, MTES 100\% (non hydrophobic, compact and continuous); medium, MTES/OTES 50/50 ratio (high packing density and optimal hydrophobicity) and right, OTES 100\% (hydrophobic and discontinuous by steric hindrance of n-octyl groups). 
Moreover, the reduced S values near 50/50 ratio would be based also on the high packing density (reduced steric hindrance between the methyl and octyl groups of reactive alkoxides) and the optimal hydrophobicity of the organosilicon polymers that coat the pore wall, Figure 3.

Finally, the slight increase of $\mathrm{S}$ values after the mentioned optimal range is due to the formation of a discontinuous reactive coating by steric hindrance (large amount of n-octyl groups) that would prevent the full cover of pore wall (this increases the water absorption), Figure 3.

To calculate the fiber saturation point $\mathrm{Kf}$, densities of untreated and impregnated wood (oven-dried at $100^{\circ} \mathrm{C} \pm 1^{\circ} \mathrm{C}$ ) were determined in laboratory. The values were $0.495 \mathrm{~g} \cdot \mathrm{cm}^{-3}$ and $0.522 \mathrm{~g} \cdot \mathrm{cm}^{-3}$ (standard deviation of 0.002 and $0.006)$ respectively. The comparable densities of all treated woods are based on the similar densities of MTES and OTES.

Figure 4 shows the Kf values vs. type of impregnant (expressed in terms of percentage level of MTES) for both cycles of immersion. The analysis of the results indicates similar trend to that presented by $\mathrm{S}$ for the two cycles (Kf I and $\mathrm{Kf}$ II). Besides, the lowest values also are observed in nearness of 50/50 ratio.

Respect to ASE, for the impregnants based only on MTES and OTES, the chemical change produced at the interface by reaction between the impregnants and the cell wall components substantially decreases the fiber saturation point, which leads to lower ASE values than those in untreated wood. For MTES/OTES mixtures, the results indicate that the reduction of the volumetric expansion due to water absorption up to the equilibrium point is significant. For the most hydrophobic organosilicic polymer, the volumetric expansion decreased between $66 \%$ and $67 \%$, whereas for that polymer with the shortest hydrocarbon chain, the reduction was between $30 \%$ and $32 \%$ (in both cases, according to the cycle of immersion considered).

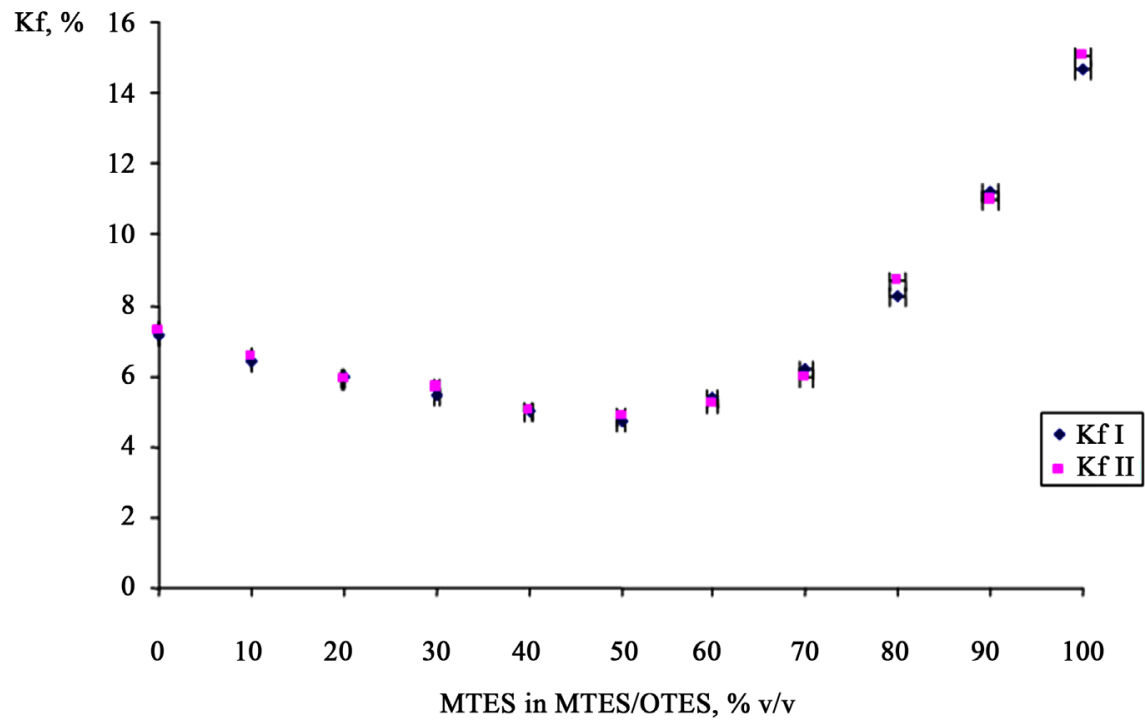

Figure 4. S variation vs. MTES concentration in the impregnant. 


\subsection{Capillary Water Absorption}

The graphical representation of water absorption $\left(W=W_{2}-W_{1}\right)$ vs. square root of time ( $\mathrm{t}$ ) allowed to obtain, during the initial phase of capillary absorption, a straight line whose slope is the coefficient of water absorption; it is usually called $\mathrm{w}$ and describes the capillary absorption rate. The $\mathrm{w}$ values are displayed in $\mathrm{Ta}-$ ble 1 .

For the results analysis, it was considered that the viscosity and the surface tension of distilled water are kept constant because all the carried tests were thermostatized. These indicate that wood treated with the impregnant based only on MTES (non-hydrophobic and chemically reactive material) did not present significant changes in the kinetics of capillary absorption (w) since the surface tension of cell wall would be little or insignificantly altered (the affinity between the molecules of cell wall and the liquid water to some extent remains unaffected).

Furthermore, for the impregnant based only on OTES (hydrophobic and chemically reactive material) a significant change is registered in the capillary absorption rate $(\mathrm{w})$ since the surface tension of cell wall was significantly altered (reduced affinity between the molecules of modified cell wall and the liquid water).

For different MTES/OTES ratios, the increase of percentage level of the hydrophobic component led to the reduction of $\mathrm{w}$ coefficient (as expected on the basis of individual behavior), i.e. towards the performance presented by the impregnant based only on OTES.

In summary, the specimens treated only with OTES displayed the lowest w coefficient: the waterproofed capillaries prevented the entry of liquid water for being hydrophobic and non-polar surfaces. In other words, the coated pores with OTES were not wetted.

\subsection{Water Vapor Permeability}

The results indicate only a slight decrease in all treated woods in relation to those untreated; this reduction ranged between 9 and 14\%, both for the two alkoxides as for all the selected ratios. The result analysis shows that the treated wood ability to dispel water vapor was not substantially changed.

It is concluded that the impregnation did not obturate the material pores since the water vapor permeability was unchanged or nearly unchanged. This advantage allows that the water vapor confined in the material can exit and thus, prevent the faults appearance generated by the condensed water inside.

\subsection{Global Analysis}

In summary, the global analysis of results indicates the following:

- The impregnants interact with cell wall components during the reactions of hydrolysis and condensation (sol-gel) produced "in situ". The impregnants based on only MTES and on MTES/OTES mixtures up to the surroundings 
of 50/50 ratio form a continuous interface, whereas those mixtures with higher content of OTES produce a slightly discontinuous interface (high length of the hydrocarbon chain generates great steric hindrance).

- The greatest dimensional stability (the lowest S and the highest ASE) was observed in those treatments that formed a continuous and highly hydrophobic interface (ratio close to 50/50), i.e. with low polarity in relation to that of water. The low volumetric expansion corresponds to decreased water absorption due to the modification of fiber saturation point.

- The coefficient of capillary water absorption (w) decreased with the increasing of OTES; although the highest water-repellency was attained with the impregnant formulated only with OTES, satisfactory values to prevent the deterioration of substrate were also achieved with the impregnants formulated with OTES levels of 50 or more (the w decreased more than $70 \%$ regarding the reference).

- The reactive impregnants form thin coatings on pores wall without reaching the obturation: this prevents liquid water penetration by capillary without diminishing the water vapor permeability; in addition, these non-occlusive treatments allow the ejection of the condensed vapor from cell lumen towards external environment because the quoted coatings have hydrophobic characteristics.

- The bibliography in general indicates that numerous researches have been carried out using silanes as impregnant for wood. This paper provides as a novelty that the silane mixtures of different length of hydrocarbon chain directly linked to silicon, in adequate proportions, substantially improve hydrophobicity and dimensional stability, without modifying the water vapor permeability, when compared with single silanes.

\section{Conclusions}

The formation of non-occlusive coatings on wood pores is supported in the following items: 1) during impregnation, the solvent mixture carries the water-repellent substances (alkoxysilanes) until depositing them on the surface of the wood pores where the polymerization by the sol-gel process takes place; 2) then, this solvent mixture, together with water and alcohol generated during reactions, is evaporated during the xerogel film formation (curing and aging); 3) the coating formation occurs in some areas surrounding to other uncoated ones, i.e. that the coating is formed on a cluster of cells enclosing an untreated core and finally, 4) the aforementioned would base the total wood protection employing only low levels of impregnant.

Organosilicon impregnants allow improving important characteristics of wood: 1) the cited non-occlusive coating keeps the water vapor permeability unaltered; 2) the alkoxysilane type defines the hydrophobicity and the continuity of coating formed on the pore wall and finally, 3) the polymeric structure formed after finishing sol-gel process incises both on the capillary water absorption and the dimensional stability. 
Finally, it is important to mention that in future researches should be studied the stability of hydrophobic interfaces against the aggressiveness of environment, since the cited interface could be degraded by prolonged exposure to weathering, and consequently to affect the dimensional stability and the capillary water absorption attained with the organosilicon impregnants. For it, different species of wood and silanes and siloxanes of different chemical natures will be used.

\section{Acknowledgements}

The authors thank to CONICET (Consejo Nacional de Investigaciones Científicas y Técnicas), UTN (Universidad Tecnológica Nacional) and CICPBA (Comisión de Investigaciones Científicas de la Provincia de Buenos Aires) from Argentina for their sponsorship to carry out this research.

\section{References}

[1] Zhu, Y., Wang, W. and Cao, J. (2014) Improvement of Hydrophobicity and Dimensional Stability of Thermally Modified Southern Pine Wood Pretreated with Oleic Acid. BioResources, 9, 2431-2445. https://doi.org/10.15376/biores.9.2.2431-2445

[2] Samyn, P., Stanssens, D., Paredes, A. and Becker, G. (2014) Performance of Organic Nanoparticle Coatings for Hydrophobization of Hardwood Surfaces. Journal of Coatings Technology and Research May, 11, 461-471. https://doi.org/10.1007/s11998-014-9576-9

[3] Petric, M.P., Knehtl, B., Krause, A., Militz, H., Pavlic, M., Pétrissans, M., Rapp, A., Tomazic, M., Welzbacher, C. and Gérardin, P. (2007) Wettability of Waterborne Coatings on Chemically and Thermally Modified Pine Wood. Journal of Coatings Technology and Research, 4, 203-206. https://doi.org/10.1007/s11998-007-9023-2

[4] Wang, X., Chai, Y. and Liu, J. (2013) Formation of Highly Hydrophobic Wood Surfaces Using Silica Nanoparticles Modified with Long-Chain Alkylsilane. Holzforschung, 394, 97-112.

[5] Chen, H., Miao, X., Feng, Z. and Pu, J. (2014) In Situ Polymerization of Phenolic Methylolurea in Cell Wall and Induction of Pulse-Pressure Impregnation on Green Wood. Industrial \& Engineering Chemistry Research, 53, 9721-9727. https://doi.org/10.1021/ie5006349

[6] Lang, Q., Zeng, B. and Pu, J.W. (2014) Characterization of Chemical Wood Modification with Melamine-Urea-Formaldehyde Prepolymer on Fast-Growing Wood. Wood and Fiber Science, 46, 1-11.

[7] Yeh, A.I., Huang, Y.C. and Chen, S.H. (2010) Effect of Particle Size on the Rate of Enzymatic Hydrolysis of Cellulose. Carbohydrate Polymers, 79, 192-199.

https://doi.org/10.1016/j.carbpol.2009.07.049

[8] Ostlund, A., Kohnke, T., Nordstierna, L. and Nyden, M. (2010) NMR Cryoporometry to Study the Fiber Wall Structure and the Effect of Drying. Cellulose (Dordrecht, Neth.), 17, 321-328.

[9] Carpita, D., Sabularse, D., Montezinos, D. and Delmer, P. (1979) Determination of the Pore Size of Cell Walls of Living Plant Cells. Science, 205, 1144-1147.

https://doi.org/10.1126/science.205.4411.1144

[10] Davison, B.H., Parks, J., Davis, M.F. and Donohoe, B.S. (2013) Plant Cell Walls: Basics of Structure, Chemistry, Accessibility and the Influence on Conversion. John 
Wiley \& Sons Ltd., Chichester.

[11] Xie, Y., Krause, A., Militz, H., Steuernagel, L. and Mai, C. (2013) Effects of Hydrophobation Treatments of Wood Particles with an Amino Alkylsiloxane Co-Oligomer on Properties of the Ensuing Polypropylene Composites. Composites Part A: Applied Science and Manufacturing, 44, 32-39. https://doi.org/10.1016/j.compositesa.2012.08.011

[12] Daud, N. and Shanks, R. (2014) Epoxy-Silica Composites Replicating Wood Cell Structure. Composites Part A: Applied Science and Manufacturing, 62, 11-15. https://doi.org/10.1016/j.compositesa.2014.03.013

[13] Canosa, G., Alfieri, P.V. and Giudice, C.A. (2011) Nano Lithium Silicates as NonFlammable Impregnants for Pinusradiate. Journal of Fire Sciences, 29, 431-441. https://doi.org/10.1177/0734904111404652

[14] Giudice, C.A., Alfieri, P.V. and Canosa, G. (2013) Decay Resistance and Dimensional Stability of Araucaria angustifolia Using Siloxanes Synthesized by Sol-Gel Process. International Biodeterioration \& Biodegradation, 83, 166-170. https://doi.org/10.1016/j.ibiod.2013.05.015

[15] Canosa, G., Alfieri, P.V. and Giudice, C.A. (2013) Dimensional Stability, Fire Performance and Decay Resistance in Wood Impregnated with Alkylalkoxysilanes. International Journal of Engineering and Innovative Technology, 3, 394-400.

[16] Altun, S., Ayhan, O.A., Şenel, A., Baysal, E. and Toker, H. (2010) Effects of Silica Gel on Leaching Resistance and Thermal Properties of Impregnated Wood. Wood Research, 55, 101-112.

[17] Chen, H., Lang, Q., Bi, Z., Miao, X., Li, Y. and Pu, J. (2013) Impregnation of Poplar Wood (Populuseuramericana) with Methylolurea and Sodium Silicate Sol and Induction of in Situ Gel Polymerization by Heating. Holzforschung, 68, 45-52.

[18] Cui, G., Liu, J., Chen, C., Li, C. and Shi, L. (2012) Study on Silane Impregnation for Protection of High Performance Concrete. Procedia Engineering, 27, 301-307. https://doi.org/10.1016/j.proeng.2011.12.456

[19] Christodoulou, C., Goodier, C.I., Austin, S.A., Webb, J. and Glass, G.K. (2013) Long-Term Performance of Surface Impregnation of Reinforced Concrete Structures with Silane. Construction and Building Materials, 48, 708-716. https://doi.org/10.1016/j.conbuildmat.2013.07.038

[20] Johannes Karl Fink (2013) Silicones Reactive Polymers Fundamentals and Applications, Chapter 8, A Concise Guide to Industrial Polymers. A Volume in Plastics Design Library, 2nd Edition.

[21] Ferrero, F. and Periolatto, M. (2013) Application of Fluorinated Compounds to Cotton Fabrics Via Sol-Gel. Applied Surface Science, 275, 201-207. https://doi.org/10.1016/j.apsusc.2013.01.001

[22] Whelan, M., Cassidy, J. and Duffy, B. (2013) Sol-Gel Sealing Characteristics for Corrosion Resistance of Anodisedalu-Minium Surface and Coatings Technology, 235, 86-96. https://doi.org/10.1016/j.surfcoat.2013.07.018

[23] Meng, X. and Ragauskas, A.J. (2014) Recent Advances in Understanding the Role of Cellulose Accessibility in Enzymatic Hydrolysis of Lignocellulosic Substrates. Current Opinion in Biotechnology, 27, 150-158. https://doi.org/10.1016/j.copbio.2014.01.014

[24] Devi, R.R., Maji, T.K. and Banerjee, A.N. (2004) Studies on Dimensional Stability and Thermal Properties of Rubber Wood Chemically Modified with Styrene and Glycidyl Methacrylate. Journal of Applied Polymer Science, 93, 1938-1945. https://doi.org/10.1002/app.20657 
[25] Hill, C.A.S. (2006) In Wood Modification Chemical, Thermal and other Processes. John Wiley \& Sons, Hoboken. https://doi.org/10.1002/0470021748

[26] Pandey, K.K. and Nagaveni, H.C. (2009) Study of Dimensional Stability, Decay Resistance, and Light Stability of Phenylisothiocyanate Modified Rubberwood. BioResources, 4, 257-267.

[27] Papadopoulos, A.N., Militz, H. and Pfeffer, A. (2010) The Biological Behaviours of Pine Wood Modified with Linear Chain Carboxylic Acid Anhydrides against Soft Rot Fungi. International Biodeterioration \& Biodegradation, 64, 409-412. https://doi.org/10.1016/j.ibiod.2010.04.002

[28] Sonowal, J. and Gogoi, P.K. (2010) Dimensional Stability, Thermal Degradation and Termite Resistant Studies of Chemically Treated Wood. International Journal of Chemistry, 2, 218-225. https://doi.org/10.5539/ijc.v2n2p218

[29] Wu, G., Lang, Q., Chen, H. and Pu, J. (2012) Physical and Chemical Performance of Eucalyptus Wood with Impregnated Chemicals. BioResources, 7, 816-826.

[30] Liu, C., Wang, S., Shi, J. and Wang, C. (2011) Fabrication of Superhydrophobic Wood Surfaces via a Solution-Immersion Process. Applied Surface Science, 258, 761-765. https://doi.org/10.1016/j.apsusc.2011.08.077 